Journal of NELTA Gandaki (JoNG), III (1 \& 2), 57-72

ISSN 2676-1041 (Print)

DOI : https://doi.org/10.3126/jong.v3i1-2.33145

\title{
Formal Email Writing Convention: Differences Between Native and Non-native Students
}

Shama-E-Shahid

Article History: Received May 21, 2020; Revised August 18, 2020; Accepted October 4, 2020; Online Published November 2020.

To cite this article: Shahid, S. E. (2020). Formal email writing convention: Differences between native and non-native Students. Journal of NELTA Gandaki (JoNG), III (1\&2), 57-72. DOI : https://doi.org/10.3126/jong.v3i1-2.33145

\begin{abstract}
The use of emails in student-faculty communication is a regulated process. The regulations are formulated in order to ensure that the correspondences are in line with the institutional requirements and to maintain professionalism. There is limited information about such regulations amongst native students (NS) and non-native students (NNS) regarding formal email writing conventions. This study examines the formal email writing conventions of NNS under a regulated environment. A purposive non-probability sampling of 10 non-native students from a British university was collected. The findings indicate that language prowess, request letter acts, and use of formality have positive impacts on the formal email writing among NNS students. It can be concluded from the above findings that teachers of ESL should pay attention to how students formulate the structure and content of emails as they directly impact their writing capability.
\end{abstract}

Keywords: email, English as second language, environment, formal email writing conventions.

\section{Introduction}

Increased interconnectedness of the world has resulted in a higher level of interaction among people of different backgrounds. Consequently, the diversity created by globalization is more prevalent in the institutions of learning such as universities where locals are instructed together with international students. English is the lingua franca hence non-native speakers have to learn it as a second language. As a result, differences have been observed between comprehension and expression aptitudes among native speakers (LI students) and foreign speakers (non-native speakers) (L2 students).

Advancement in technology has increased the efficiency of the communication process among individuals. As a result, prior instances of face to face communications have been continuously phased out by the newest forms of information sharing. One of the new modes of interaction is the use of emails where a majority of the shared information is in an electronic format but retains the ability for attachment of multiple files of different forms. The inexpensive, fast, convenient and environmentally friendly nature of emails have popularized their use in college education (Peck, 2014, p. 15). Consequently, the use of formal emails has gained popularity in professional and academic contexts due to its efficiency. Emails are consistently used as a means of communication and interaction among students, the professors and 
the respective faculties (Danielwicz-Betz, 2013, pp. 24-5). However, the concept of language pragmatics in emails sent by university students when they make requests to their professors and faculty remains a controversial issue. Danielwicz-Betz (2013, p. 25) maintains that there are no specific guidelines that inform the choice of form and style of constructing email messages among students.

There are notable differences between students who use English as first language and those who use the English as a second acquired language with respect to the pragmatics of language used in email conversations. The differences can be attributed to unawareness of students regarding the identity of the recipients with whom they wish to converse. As a result, ESL learners often face uncertainties regarding the decorum on linguistic forms to be used in emails and academic settings. Hendricks argues that the divergence in the language used by ESL students compared to the native students can be observed in basic grammatical competence and practical competencies in business writing skills (2010, p. 222). As a result, ESL students have glaring inadequacies of correct modifications that should be followed in the norms of academic and formal communication settings.

The insufficient alterations in the communication of ESL students are a result of limited and nonelaborate strategies of politeness (Hendricks, 2010, p. 222). Furthermore, Krulatz and Park identify the use of directness in the communication of Norwegian and native American speakers through the use of direct words such as 'want' (2016, p.39). Imperatives implied by the improper use of punctuations also contribute to the level of directness, differences observed between email communications of native speaking students and the NNS learners. Other factors that may influence the divergence found between the use of language in emails by native speakers and NNSs include the practice level, anxiety level when writing different information, and culture shocks.

\section{Review of Literature}

Several studies have been conducted to investigate the language learning process by ESL students and their proficiency based on the nature of email exchange between students and faculty (Alkhalaf 2014; Bou-Franch, 2011; Tajeddin \& Pezeshki, 2014). From the studies, various theories that explain language acquisition are behaviorism, innatism, and interactionism; these theories will shed more light on how language is acquired when using emails and how this translates to improved or deteriorated academic writing skills (Alkhalaf, 2014; Bou-Franch, 2011). Alkhalaf (2014, p.6) recognizes that the SLA theory implies that human beings have retained the capacity to acquire language skills needed to converse and interact with other persons who use the same language. The learning of a second language occurs through formal instructions or informal means such as interaction with native speakers (Alkhalaf 2014, p.7). Achieving competency in a second language occur after the establishment of a first language; this is likely to impact on the manner in which the use of emails influences language usage among ESL students.

\section{Innatism}

The reasoning behind this biological argument is that a child is born with the innate/inborn abilities to acquire the skills to learn a language; both first and second languages (Dolati, 2012, p.754). Dolati (2012, p.759) argues that the innate ability to learn languages lies on the "predisposition that our brains 
have a certain structure for language'. Consequently, the innatism theory underpins the development of second language skills among learners of different age groups.

\section{Behaviourism}

Behaviourism is a psychological theory. In relation to language, this theory stipulates that people acquire language skills through imitations and repetitions (Rosen, 2010, p. 353). On the other hand, behaviourism theory suggests that repetition methods can be utilized in the learning of second languages. Bahrani and Sim (2012, p.144) assert that language exercises and practice by learners under the behaviourism theory take place under planned and pre-designed activities like the use of video resources, even in the informal settings. Furthermore, drills such as exercises and tests form part of the repetitive process which makes up the habits of learning the second languages. Feedback from educators serves as the reward and reinforcement for the learning process.

\section{Interactionism}

Interactionism theory is often preferred in the explanation of second language learning where people are encouraged to interact with native speakers (Alkhalaf, 2014, p. 10). The interaction with native speakers means that when the output of their conversations is not understandable, second language learners will be forced to retry the communication (Dolati, 2012, p. 756). Furthermore, native speakers may realize the mistakes that the NNS individual makes and they correct them as they try to present their message, which reinforces the learning process of the second language. The other argument supporting the interactionism theory in SLL is that interaction with advanced scholars ensures that L2 students acquire the needed skills in both spoken and written language skills (Gan, 2013, p. 234).

The use of email as a means of communication in academia is a form of interaction between academics and the students. Consequently, the interaction between NNS students and their professors, who are advanced scholars with higher knowledge of language use, present a chance for them to exercise their learning of the desired language (Gan, 2013, p. 234). When professors deem that the messages written by students are not understandable, students are forced to reconstruct to convey their intended meaning. Conversely, the strict demands and guidelines by some instructors on the composition of email messages during the interaction process reinforces the language learning process (Gan, 2013, p. 234). As a result, interactionism arguments support the fact that email interaction between L2 students and the faculty impacts the development of writing skills among such learners (Gan, 2013, p. 235).

Following the continued use of emails to communicate in the academic setting, scholars have classified email writing as a genre while considering the repetitive patterns used in the exchanges between students and instructors (Galabi, 2011, p. 3; Cowan, 2009, p. 306). The identification of the use of emails as a genre prompts a definition of the required textual characteristics such as grammar and spellings as well as the comparison between the observance of such requirements by ESL and EFL students (Hasan and Akhand, 2011, p. 78). Much attention has been paid to the academic writing of ESL students with respect to the genre; this is because the frequent use of emails between the faculty and students, being a formal interaction, has an impact on how ESL students acquire their academic writing skills. Therefore, it 
is crucial to establish written emails from a faculty point of view on the learning and teaching of English language.

\section{Email as a Genre}

Understanding email writings as a genre requires the consideration of context. Galabi (2011, p. 3) identifies writing genres as those situations characterized by recurrent patterns in the usage of language. As a result, different social scenarios demand different genres in response to the fact that "they are constructed socially and depend on unique contexts' (Galabi, 2011, p. 3). There are diverse contexts readily observed in email conversations ranging from personal to professional. As a result, personal contexts may have fewer demands regarding the construction of email and may fail to adhere to the general email features (Galabi, 2011 , p. 4). On the other hand, professional and academic contexts require the adherence to specific guidelines in writing emails (Ren, 2016, p. 11). As evidenced in the adoption of different writing styles in other genres such as letters, the same case applies to email writing. Socially accepted norms to converse formally must be observed. As a result, professional email conversations should observe politeness, and correct grammar usage as the absence of these factors leads to a possible misunderstanding of the sender by the recipient (Ren, 2016, p. 11).

In the same context, Stephens, Houser \& Cowan (2009, p.310) mention that the interactions between students and teachers are formal and have a pattern that is based on and follows specific conventions and appropriateness in language, and the breach of these conditions results in negative repercussions. Some of the negative feedbacks resulting from lack of proper decorum in the use of email as a means of communication are low opinions about the message by the student, low credibility associated with the message and reduction in the probability of a professor in complying with the request being made (Stephens et al. 2009, p.310). As a result, it becomes imperative for students to understand email writings as a genre which requires the consideration of context while drafting messages.

\section{General Email Textual Features}

Several studies have been conducted to investigate textual email writing. Some of these features include:

Openings. Multiple research studies have been done regarding the use of openings in email conversations; the use of openings was mainly dependent on three main factors namely cultural background, language proficiency, and the sequence of messages (Bou-Franch 2011; Ko Eslami, and Burlbaw 2015; Tajeddin \& Pezeshki, 2014). Bou-Franch (2011, p.10) discovered that 93 percent of all emails from native Spanish students contain a form of official opening (such as dear Sir/Madam) regardless of the sequence such as is it the first message in the conversation thread or subsequent message.

Regarding cultural background, Tajeddin \& Pezeshki (2014, p. 269) compared Iranian and American usage of email using English language and observed that both groups tend to use official openings. However, the authors note that Iranian students use small talk in the openings while other openings are denser. Cook (2016) further confirms that cultural differences affect the types of openings that an individual use while writing an email. In view of the language proficiency, Economidou-Kogetsidis (2011, p. 11) report that 
the level of proficiency in English determines the use of openings and the use range from direct omission, grammatically wrong but acceptable, to those openings that disregarded title and may be considered offensive such as the use of 'Mrs.' instead of 'Dr.' or 'professor.' This paper will focus on the types of openings rather than the presence or absence of the element.

Closings. Closings are categorized into three aspects: pre-closing, farewell, and self-identification (Ko, Eslami, \& Burlbaw, 2015, p. 5). Cultural differences also affect the variations of closings used where NNS students (Iranian) used a diverse composition of closings while American students used standardized forms of closings such as regards, yours sincerely, and so on (Eslami, 2013, p. 89). Furthermore, Iranian students use longer closing moves that ranged from pre-closing markers of thanking, farewells, apologizing, to self-identification (Cook, 2016). However, closings were not prone to language proficiency mistakes.

Email Request Head Acts. Whuhan Zhu (2012, p. 219) defines email request head acts as the minimum elements required to achieve the desired output from a request. Head acts represent the central part of a request sequence, and they are classified by the request strategies and the different categories including direct (e.g. I want to meet you), conveniently indirect (e.g. are you available on next Thursday?) or hints (e.g. enclosed is the attachment of my student profile) (Ko, Eslami, \& Burlbaw, 2015, p. 8). In a study conducted by Tyter (2015), the researcher compared the differences between request strategies used by L1 and L2 students in academic settings. According to the findings, it was discovered that native speaking students used syntactic modifiers (embedding, i.e. I would appreciate if you could help me) while ESL students employed lexical modifiers (e.g. subjectivizer, such as- I think, I wanted to know, I was wondering if, etc. and consultative device, such as- is there any chance? do you think that? etc.) in their email request strategies (Tyter, 2015, p. 52). As a result, NNS students tend to use more directness in their head acts while native speakers were not oriented towards conventionally indirect and use of hints.

\section{Extra-Linguistic Factors}

The application of deadlines and frequency of required academic texts imply that time and likelihood of writing are considered essential in academic writing (Schüppert \& Gooskens 2011; p. 332). In the study by Tyter (2015, p.55), it was found that NNS students were recorded to take more time in composing their emails compared to native speakers while their likelihood of writing emails was lower compared to EFL students. To conclude, it is apparent that the academic writing language can be a first or a second language to the student, and ESL and EFL students have different attitudes towards the English language (Eshghinejad \& Moini, 2016). Therefore, the investigation of writing emails in the field of academia needs to incorporate the identified factors.

Context. Social context cues are essential in the communication between individuals as they establish the required protocol and observe the politeness accorded to hierarchy (Wang, Walther \& Hancock, 2009, p. 60). In the field of academia, the protocol indicates that members of the faculty are higher ranking personnel compared to all students. As a result, written communications from students to professors should contain various social context cues to reflect the difference in social hierarchy between them (Alvídrez et al. 2015, p. 534). While native speakers of English may effectively employ the different social context 
rules, misuse among NNS students often creates aspects of impoliteness in their communication between them and their professors.

Grammar. Grammar issues in email exchanges between the faculty and students are common in both EFL and ESL students but L2 scholars are more likely to commit serious grammatical errors compared to the EFL students (Island, 2016, p. 2478). Abdeen (2017, p. 95) assert that ESL students are more likely to commit serious text-level grammatical errors than sentence-level grammatical errors. These grammatical errors can be divided into text-level and sentence-level elements.

Text-level grammar errors involve the inappropriate use of words to create a sentence, thus, losing the meaning of the intended message. Candlin \& Hyland (2014, p. 11) point out that every text contains a structure which is meant to pass an information in a specific way. As such, the commission of such errors in academic writing among students results in utter confusion and consequent misunderstanding by the reader. Text-level grammar is also characterized by the inappropriate choice of words by students writing academic materials such as articles or email correspondences. Further, Bailey (2014, p. 16), explains that an individual is required to use both verbs and nouns to create a comprehensible sentence. The failure to adhere to these rules often result in losing the intended meaning.

Sentence-level errors on the other hand entail arranging words and clauses in a way that does not make sense when read. Purpura (2013, p. 9) points out that a writer is supposed to consider not only the main clauses but also the compound or complex clauses when constructing a sentence in order to construct a logical statement. In his view, Andrews (2010, p. 2) asserts that text-level grammar has more influence on an individual's knowledge of a language compared to the sentence-level grammar, thus, teachers should prioritize improving the former while teaching grammar. According to the author, L2 students are more likely to make text-level than sentence-level grammatical errors. By contrast, however, Datchuk and Kubina (2013, p. 180) conclude that a majority of ESL students struggle with sentence-level adjectival mistakes more than any other aspect of writing. Students are fond of using short forms of words such as LOL for "laughing out loud" and 4 instead of "for" which affects their text-level grammar negatively (Ikeguchi 2013, p. 66). The trend can be attributed primarily to overgeneralization and ignorance of rule restriction (Tak 2014, p. 433). Text-level grammatical errors that are commonly made by L2 students include verb confusion (verb-subject agreement).

Other grammatical errors include wrong tense, word order, incorrect choice of word forms, and preposition errors (Matsuda \& Cox, 2011, p. 5; Yoosawat \& Tangkiengsirisin, 2016, p. 34). Furthermore, Island (2016, p. 2478) identified various grammatical issues that can be observed to ensure professional etiquette and they include polishing through proper editing. Singh et al. (2017, p. 16) maintained that ESL students are more likely to make serious grammatical errors than EFL students because they were also taught by ESL teachers or the students have a cognitive inability to comprehend various subjects within the grammar system such as subject-verb agreement, tenses, and essential and nonessential clauses. Therefore, the remedies to improving grammar usage by ESL students in their academic writing include training ESL teachers adequately and employ strategies that will ensure students comprehend the various concepts aptly (Singh et al. 2017, p. 16). 
Additionally, in a study, it was discovered that an email without spelling, grammar, and punctuation errors conveyed a professional tone (Foral et al. 2010, p. 8). In another study, it was discovered that ESL students who were allowed to use online resources to write an essay showed a significant improvement in how they expressed their thoughts with respect to the grammar rules (Hsieh, 2016, p. 115). Therefore, the combination of technology and collaboration portrayed in a classroom learning environment that is facilitated by the use of Internet resources is a great resource for enhancing grammar improvement among ESL students.

\section{Purpose of the study}

The frequent usage of emails in academic settings by ESL students indicates the need for educational and formal language in their communications. Classrooms and system-set evaluation mechanisms may reveal that ESL students are proficient in their use of academic writing due to their increased preparedness before examination periods. Standardized tests fail to reveal the ability of students to contextualize interaction scenarios (Roever, 2011, p. 9). However, the purpose of this study is vital for the following reasons:

- The language used in emails unveils ESL learners' contextual and pragmatic capabilities in making academic and formal conversations.

- The corrections and pointers in the correct usage of academic writing in formal setting present educators with chances to informally teach ESL students regarding the proper usage of formal language in an educational setting.

- Instructors can use emails as an integral means of increasing students' practice in academic writing skills.

- Instructors can use emails as an approach of communication to ensure continuous and individualized assessment regarding the growth of students in professional communication skills.

\section{Research questions}

- How do formal email writing conventions by non-native speaking students differ from the conventions of the native students?

- What are the differences between NNS and NS students that can be characterized in their formal email writing conventions?

\section{Methods and Participants}

A cross-sectional design approach under qualitative research is used in this study where the researcher follows the study to measure the exposure and the outcomes (Setia, 2016, p. 261). This study is about understanding the difference of email writing conventions between NNS and NS students, thus, this type of study requires a methodological flexibility to offer a comprehensive and detailed view of the phenomenon under investigation. Also, the study requires consent from the informants. Participants consented to quote the texts for use in the study. Even so, the identity and personal information of the participants in this study has been withheld, for personal and ethical reasons. Therefore, it was easy to collect the authentic email samples. The researcher used participants' email copies to collect data on their 
naturally occurring behaviors of drafting and sending emails to their academics in the context of academia. The data was analyzed using a linguistic analysis as elaborated further in the subsequent sections of this paper. A purposive non-probability sampling was used to obtain 10 NSS students from a British University to participate in this study. The selected participants were asked to present five emails that they sent to the faculty seeking a clarification or an appointment or any other form of request. A total of 50 emails were collected and documented in one file to form the corpus.

\section{Data Collection}

Ten NNS students were purposively sampled using a non-probability strategy. Six of them were males and the rest females. Eight of the students were Asians and two were from Africa. Their mean age was twenty-three years. The ten students were then requested to provide five emails each that they have sent to their professors in a formal context. The emails were then collected and documented in one file. A total of 50 emails were collected over a period of one week. The emails were then analyzed linguistically using guidelines from previous studies.

The ten participants were obtained through well-defined inclusion and exclusion criteria. The criteria for selecting participants included the following; non-native English speakers, have a regular formal communication with the academics using email, and must be a university student. The exclusion criterion also entailed the last time the student contacted to their academics. NNS students who contacted their academics more than six months ago were excluded from the study. Further, NNS students who have been speaking English for the last ten years were also excluded.

This study involved the use of both primary and secondary data even though a mono method research strategy was employed. The 50 emails collected above comprise the primary data. A collection of secondary data was also collected using an advanced web search strategy. After identifying how the NNS students compose the emails that they send to their academics regarding emails' openings and closings, email request heads, extra-linguistic factors, punctuations, spellings, context, and grammar; keywords and key-phrases were used to search the Internet for journal articles, educational books, and other resourceful materials to do a comparison helpful in identifying how formal email writing conventions by non-native speaking students differ from the conventions of the native students. The advanced search strategy included the use of Boolean connectors in various online databases particularly EBSCOhost, T and F online, JSTOR, and many others. Other sites such as Google Books and Google Scholar were used to search the materials. The Boolean connects that were used include 'AND,' 'OR,' and 'AND NOT.'

\section{Data Analysis}

The primary set of data is analyzed in comparison with the secondary data as proposed by Peck (2014, p.17) who asserted that email composition should be formed in a professional language and with considerations given to the writer or writer's position (Peck 2014, p.17). The process of analyzing email requests as proposed by Chen \& Baker (2010) entails examining the entire orientation of the email, that is, the general features in the text (general email textual features) such as openings and closings. It also involves assessing samples of the request sequence which majorly focus on head acts. The general 
content of the NNSs' email to faculty members is also considered to determine the margin of directness or indirectness which in turn would influence the judgment of the politeness of the email. Overall, data were analyzed using linguistic analysis. Before the emails were analyzed, they were documented in one document as a corpus. Barceló-Coblijn et al. maintained that currently there are no specific methodological approaches to carrying out a linguistic analysis (2017, p.3). The latest software that can analyze language effectively is called Netlang. After analyzing the secondary data, the researcher did linguistic analysis. Data from previous studies, educational books, magazines, and other resourceful materials were used to make the comparison.

\section{Results}

This study conducted a simple and unique linguistic analysis based on Chen \& Baker's (2010) approach. This study utilizes a corpus of 50 emails sent to the faculty by 10 NNS students. The entire orientation of an email message can be determined by examining the following aspects: emails' openings and closings, email request heads, extra-linguistic factors, punctuations, spellings, context, and grammar.

\section{Openings}

All the students are well-informed on recognition and use of salutations which is observed throughout their emails. However, the fifth student considers the use of grammatically informal and unacceptable phrases such as 'Dear Mam' instead of 'Dear Miss/ Mrs.' (See Appendix 1). Depending on the context, five students use greetings as listed below, but they also omit the element in sequential emails.

Table 1

Summary of Greetings Used by the Students

\begin{tabular}{lll}
\hline Student No. & Email number & Number of greetings used \\
\hline 1 & 1 & 1 \\
2 & 4 & 1 \\
5 & 5 & 1 \\
6 & 2 & 1 \\
8 & 2 & 1
\end{tabular}

On the other hand, the third, fourth, seventh, ninth and tenth student does not recognize the use of greetings at all. Additionally, this finding corresponds to Hallajian \& David's (2014) findings which indicate that most students often start with an opening, which can be considered as a "greeting" or "selfexplanatory" (Hallajian \& David 2014, p.87).

\section{Closings}

Most students are familiar with pre-closing markers such as 'thank you,' 'looking forward to hearing from you,' 'yours sincerely' 'good-bye' and such (See Appendix 1). The same is omitted in sequential emails of a number of the students, for instance, the fifth email of the third student, the third email of the sixth student and the fourth emails of the ninth and tenth students. Findings of this study regarding this aspect coincide with findings of prior studies. For example, a study that was conducted by Hallajian \& 
David indicated that students mostly use closings in their first emails but fail to continue using them in the sequential emails (2014, p.88). This phenomenon is currently unexplored and there is a need to explore as it has potential implications in teaching English as a second language.

\section{Request Letter Acts}

The findings of this present study of email request acts correspond to the CCSARP framework of Blum-Kulka, House \& Kasper (1989) which this study followed. The findings from this study suggest that most NNS students (49\%) apply direct request strategies to their lecturers.

Table 2

Percentage of Requestive Directness $(N=50)$

\begin{tabular}{lll}
\hline Request type & Request strategies & Percentage \\
\hline \multirow{3}{*}{ Direct request } & Imperatives & $13 / 50(26 \%)$ \\
& Direct questions & $1 / 50(02 \%)$ \\
& Want statement & $6 / 50(12 \%)$ \\
& Expectation statement & $6 / 50(12 \%)$ \\
& Need statement & $3 / 50(06 \%)$ \\
Conventionally indirect requests & Total & $29 / 50(49 \%)$ \\
Hints & Query preparatory & $10 / 50(20 \%)$ \\
Others & Strong/mild hints & $8 / 50(16 \%)$ \\
\hline
\end{tabular}

These findings also correspond to those of Ko, Eslami \& Burlbaw (2014) who investigated the pragmatic development of NNS students in requestive emails. The authors discovered that NNS students use different request letter acts from those of native English speakers who are students.

\section{Linguistic Prowess and Grammar Rules}

Most of the emails were composed using simple words that are easy to comprehend by the reader. It is also notable that the NNS students who participated in this study observed grammar rules apart from a few mistakes. An excellent example of an email that uses simple language with flawless grammar is:

I am writing this time for a query. As far as my visa application process is pending for a decision,

I would like to know about the payment system of my accommodation fees. Can I pay the whole accommodation fees in one single instalment, instead of three separate instalments?

Thanks in advance.

From the example above, it is notable that the second student's third email has flawless grammar and uses simple words to communicate her point. It is to be mentioned that this student's other emails are also fairly accurate (Refer to Appendix 1 for more details). However, there are some other students who accidentally had grammatical errors and their language was complicated. An excellent example is the email below (student 8, mail one). This is to be noted that this student's other mails also contained some errors.

Greetings!!! I am hereby too pleased to receive this email as to enroll in PHD program which was always my dream. Please let me know the criteria for admission. However, after completing MSC 
in Project Management, I haven't yet appear in the IELTS exam and will be appear my April. Is it possible to enroll in the program without IELTS? Moreover what is the tuition fee structure?

Waiting to hear from you.

The above email has a lot of grammatical errors including tense confusion. The email was also poorly punctuated, thus, rendering it a poor form of communication in the context of a student-faculty interaction. This can result in the professor developing a negative perception. Many students will naturally adhere to that format to receive responses and feedback from the professor. Further, there are some emails that pass the intended messages clearly despite the multiple errors such as grammar and punctuation that they contain. However, some emails have serious mistakes just like the one shown above.

Overall, the average outlook for the language prowess and grammar usage among NNS students when emailing was outstanding. Most of the students wrote emails in a well-articulated manner and they displayed their prowess in the language through their writing. Most of the emails could be accepted in a formal setting based on the guidelines provided by Peck (2014). However, the trend observed from this analysis is that as much as the larger portion of the participants portray themselves as being average, there are also severe cases. This trend should also be examined in a similar study among students who are native English speakers. As well, this will have significant implications for the English Language Education. Nonetheless, this finding corresponds to the findings of Jewels and Albon (2012) that most NNS students often use a simple language with little to a few grammatical and punctuation errors (p.12). The aim of comparing each finding with the findings of prior studies is to try to put the phenomenon under investigation in the context of what is already known.

\section{Formality and Informality}

It was observed that most NNS students write formal emails to their professors based on the guidelines provided by Peck (2014). Most of them address their academics using titles such as 'Dear Sir/ Madam'. Only a few students referred to their professors using their first names. For example, the seventh student never used a title but instead referred to the professors using their first names. This act may sound rude and impolite, but it is also important that one understands the cultural underpinnings that may have influenced the student's choice of openings.

Collectively, the results of the linguistic analysis indicate that the participants of this study have a certain level of proficiency in writing formal emails. This conclusion is based on the grounds that they registered an outstanding performance with respect to most of the aspects of this linguistic analysis. They only notable weaknesses lie on the punctuation and a few grammatical errors. Thus, there is a need to find a similar research report that examined the above aspects among students who are native English speakers.

The second phase of data analysis yielded divergent results. Hallajian and David (2014), who looked specially at Iranian students studying in Malaysia, were used in analyzing the findings of openings and closings. Regarding the openings, the comparison of primary data and secondary data confirmed that indeed most NNS students mostly use openings in their emails to the academics. Openings can further be classified into greetings and self-identification. Indeed, from the corpus, it is evident that most of the 
openings are components of greetings or self-identification. Another notable thing is that openings or the greetings and self-identification phrases or statements can be grammatically incorrect or be offensive depending on the titles used.

Further, a comparison of secondary data and primary data revealed that most NNS students use closings when writing emails to their professors in the context of academia. Additionally, closings can further be subdivided into pre-closing, farewell, and self-identification (Hallajian \& David, 2014, p. 87). These categories of closings do not necessarily exist in emails, but they are the most dominant across various cultures. Further, it has been discovered that students from certain cultures such as Iraq tend to use formal styles of communication and use more thanking, apologizing, and farewell than American natives (Hallajian \& David, 2014, p.91). Despite the fact that several recent studies have explored this topic previously; no current study has examined how the use of closings relate to this study. Therefore, a future study examining the use of closings in emails in student-faculty interaction should be conducted.

No research has examined the relationship between the use of directness and indirectness and academic writing from the perspective of NNS students. However, several studies have examined directness and indirectness in many languages including English and Russian. An investigation revealed that native speakers tend to use indirectness in their requests whereas NNS use directness when making requests (Almegren, 2017, p. 243). This finding partially agrees with the outcome of this study.

Areas directly related to academic writing include formality and informality and language prowess and grammar rules. A study indicated that the relationship between the professor and the student determines formality and informality in email composition (Shim, 2013, p. 223). The investigation also revealed that involuntary usage of informal language in a formal context affects the decorum required in academic writing (Shim, 2013, p. 223). This study indicated that most NNS students use formality when formulating emails to the faculty.

\section{Discussion}

This section summarizes the general remarks concerning the research and findings. Second-language acquisition is affected by various factors among them the first language interference, environmental elements of interaction, and mastery of content. Many theories have come up with tenets to explain how the second language is acquired. The linguistic analysis of the emails showed that most NNS students could send structurally acceptable emails to their academics. Besides, most of them are also able to generate appropriate content for the emails. Some of the challenges that were noted among the NNS students or the study informants are various barriers to effective learning. These barriers differ from one context to another, and that is why different NSS students have different levels of mastery of English language.

Besides, the findings of this study also showed that NNS students' language prowess, use of request letter acts, and use of formality are directly related to the level of their academic writing skills. Students who have satisfactory language prowess, the ability to apply directness and indirectness in emails appropriately, and can embrace formality in emails to the faculty can write academically efficiently. It is evident that the three aspects that relate to formal email writing conventions mentioned above are also pre-requirements for effective 
writing. For example, one must have the exceptional language ability to write excellent academic papers.

\section{Conclusion and implications}

The central assumption that was made in regards to this study to what extent NNS students formal email writing conventions differ from the NS students. Due to time constraints, the researcher opted for a cross-sectional design as a way of observing the corpus that consisted of 50 emails of 10 NNS students from a renowned British University. Otherwise, a longitudinal design study would have provided a comprehensive perspective of the phenomenon under investigation because of time adequacy and methodological advantages. Even though this study is characterized by significant methodological shortcomings, its findings can make a small contribution in teaching English as a second language. Besides, the results of this study can serve as the primary informant of future studies intending to explore this problem further using more structured and comprehensive research methodologies. Moreover, the best research methodology for this study would be the use of mixed methods. The findings of this study suggest that, to perfect their writing skills, L2 students should work harder to learn the language used in academic work besides attending the regular curriculum involving professors, lecture attendances and assignment submission.

Students in the same institution and location can attend symposiums organized amongst themselves. Those performing better can help the less performing at different levels to improve their English language competence. L2 students can also take the initiative to empower each other in academic performance. Empowerment encourages a student who raises his or her interest in self-development. The students can get a professor or a faculty member willing to work with them to achieve the goal. Students can engage in practical public speaking before the others and one-on-one participation in in-depth, extensive discussions. Public speaking and open talks enhance the development of speaking and build the confidence while minimizing anxiety about making errors. Students should also have a humble attitude towards positive and constructive criticism. Also, it has been observed that ESL students in some institutions perform better compared to other institutions due to the surrounding and the effect the surrounding has on them. If the native speakers embrace and accommodate the NNS students at a personal level, the NNS students will develop a more in-depth focus in the foreign language. The teachers should have strategies of engaging native speakers to accommodate NNS students at personal levels for improved learning. Furthermore, teachers need to be well informed on how to execute various instructional approaches efficiently. Teachers should also consider the use of mobile learning to facilitate second language acquisition.

While doing the linguistic analysis, the researcher coincidentally noted some trend regarding the content and structure of emails and the average number of words used by email. A well-structured study should be conducted to confirm this trend., Further study is needed to be established whether the trend of omitting the closing marks is also similar among students who are native speakers. Additionally, further research should be conducted to determine why NNS students often forget to include an acceptable closing tag at the end of their sequential emails. Regarding grammatical errors, the situation can be attributed to the notion that students do not have enough time to interact with their professors, thus, they are not well 
versed with the aspects that influence the composure of emails to the faculty members. Moreover, future study on this topic should be conducted using different methodological strategies.

\section{References}

Abdeen, W. (2017). The effect of the academic attainment of esl teachers on evaluation of esl learners' errors: educational degree-based study. SSRN Electronic Journal, 8(1), 94-107.

Alkhalaf, S. (2014). An examination of English instructional strategies at University level in Saudi Arabia. Masters. State University of New York.

Almegren, R. (2017). speech act of greeting for american native speakers of English and Saudi Native speakers of Arabic: a comparative study. International Journal of Applied Linguistics and English Literature, 6(7), 243.

Alvídrez, S., Piñeiro-Naval, V., Marcos-Ramos, M. \& Rojas-Solís, J. (2015). Intergroup contact in computer-mediated communication: The interplay of a stereotype- disconfirming behavior and a lasting group identity on reducing prejudiced perceptions. Computers in Human Behavior, 52, 533540.

Andrews, R. (2010). Teaching sentence-level grammar for writing: the evidence so far. Beyond the grammar wars. A resource for teachers and students on developing language knowledge in the English/Literacy classroom, 91-108.

Bahrani, T. \& Sim, T. (2012). Audio-visual news, cartoons, and films as sources of authentic language input and language proficiency enhancement. TOJET: The Turkish Online Journal of Educational Technology, 11(4), 56-64.

Bailey, S. (2014). Academic writing: a handbook for international students. Routledge.

Barceló-Coblijn, L., Serna Salazar, D., Isaza, G., Castillo Ossa, L. \& Bedia, M. (2017). Netlang: a software for the linguistic analysis of corpora by means of complex networks. PLOS ONE, 12(8), e0181341.

Blum-Kulka, S., House, J., \& Kasper, G. (1989). The CCSARP Coding Manual. In S. Blum-Kulka, J. House, \& G. Kasper (Eds.), Cross-cultural pragmatics: Requests and apologies (273-294). Norwood, NJ: Ablex.

Bou-Franch, P. (2011). Openings and closings in Spanish email conversations. Journal of Pragmatics, 43(6), 1772-1785.

Candlin, C.N. \& Hyland, K. (2014). Writing: texts, processes and practices. Routledge.

Chen, Y.H. \& Baker, P. (2010). Lexical bundles in L1 and L2 academic writing.

Cook, V. (2016). Second language learning and language teaching. ( $5^{\text {th }}$ ed.) Abingdon, Oxon: Routledge.

Cowan, J. (2009). Academic writing and publishing - by James Hartley. British Journal of Educational Technology, 40(4), 303-326.

Danielewicz-Betz, A. (2013). (Mis)use of email in student-faculty interaction: Implications for university instruction in Germany, Saudi Arabia, and Japan. The Jalt Call Journal, (1), 23-57.

Datchuk, S.M. \& Kubina, R.M. (2013). A review of teaching sentence-level writing skills to students with writing difficulties and learning disabilities. Remedial and Special Education, 34(3), 180-192.

Dolati, R. (2012). Overview on three core theories of second language acquisition and criticism. Advances 
in Natural \& Applied Sciences, 6(6), 752-762.

Economidou-Kogetsidis, M. (2011). Please answer me as soon as possible: pragmatic failure in non-native speakers'e-mail requests to faculty. Journal of Pragmatics, 43(13), 3193-3215.

Eshghinejad, S. \& Moini, M. (2016). Politeness strategies used in text messaging. Sage Open, 6(1), 1-13.

Eslami, Z.R. (2013). Online communication and students' pragmatic choices in English. Lodz Papers in Pragmatics, 9(1), 71-92.

Foral, P., Turner, P., Monaghan, M., Walters, R., Merkel, J., Lipschultz, J. \& Lenz, T. (2010). Faculty and Student Expectations and Perceptions of E-mail Communication in a Campus and Distance Doctor of Pharmacy Program. American Journal of Pharmaceutical Education, 74(10), 1-11.

Galabi, L. (2011). Student use and teacher requirement of e-mail conventions. Masters. The American University in Cairo.

Gan, Z. (2013). Understanding English speaking difficulties: an investigation of two Chinese populations. Journal of Multilingual and Multicultural Development, 34(3), 231-248.

Hallajian, A. \& David, M. (2014). "Hello and good day to you dear Dr. ..." greetings and closings in supervisors-supervisees email exchange S. Procedia - Social and Behavioral Sciences, 118, 85-93.

Hasan, M. \& Akhand, M. (2011). Approaches to writing in EFL/ESL context: balancing product and process in writing class at tertiary level. Journal of NELTA, 15(1-2).

Hendriks, B. (2010). An experimental study of native speaker perceptions of non-native request modification in e-mails in English. Intercultural Pragmatics, 7(2), 221-255.

Hsieh, Y. (2016). A case study of the dynamics of scaffolding among ESL learners and online resources in collaborative learning. Computer Assisted Language Learning, 30(1-2), 115-132.

Ikeguchi, C. (2013). Explorations on the issues involved in classroom emailing. [ebook] Tsukuba Gakuin University, 61-68. Available at: http://www.nus.edu.sg/celc/research/books/4th\%20Symposium\%20 proceedings/9).\%20Cecilia\%20Ikeguchi.pdf.

Island, H.D. (2016). OMG! you said what in class? TMI! College student and professor perceptions of professional etiquette Violations. Universal Journal of Educational Research, 4(10), 2477-2482.

Jewels, T. \& Albon, R. (2018). We Don't Teach English, We Teach in English: Teaching non-native Englishspeaking University students. Learning and Teaching in Higher Education: Gulf Perspectives, [Online] 9(1), 1-29. Available at: http://the.zu.ac.ae [Accessed 24 Mar. 2018].

Ko, S.W.H., Eslami, Z.R. \& Burlbaw, L.M. (2015). Investigating non-native English-speaking graduate students' pragmatic development in requestive emails. International Journal of Society, Culture \& Language, 3(1), 1.

Krulatz, A. \& Park, K. (2016). Fostering Pragmatic Competence: Strategies and Materials for Email Writing.

Matsuda, P.K., \& Cox, M. (2011). Reading an ESL writer's text. Studies in Self-Access Learning Journal, 2(1), 4-14.

Purpura, J.E. (2013). Assessing grammar. John Wiley \& Sons Inc.

Peck, A. (2014). OMG RU really going to send that? Email communication with students. Essays from 
E-xcellence in Teaching, XIII, 15.

Ren, W. (2016). Pragmatic strategies to solve and preempt understanding problems in Chinese professionals' emails when using English as lingua franca communication. International Journal of Bilingual Education and Bilingualism, 1-14.

Roever, C. (2011). Testing of second language pragmatics: past and future. Language Testing, 28(4), 463481.

Rosen, R.S. (2010). American Sign Language curricula: a review. Sign Language Studies, 10(3), 348-381.

Schüppert, A. \& Gooskens, C. (2011). The role of extra-linguistic factors in receptive bilingualism: Evidence from Danish and Swedish pre-schoolers. International Journal of Bilingualism, 16(3), 332-347.

Setia, M. (2016). Methodology series module 3: cross-sectional studies. Indian Journal of Dermatology, $61(3), 261$.

Shim, Y.S. (2013). International faculty perceptions of requestive emails by Korean university students. Multimedia-Assisted Language Learning, 16(4), 111-131.

Singh, C., Jageer Singh, A., Abd Razak, N. \& Ravinthar, T. (2017). Grammar errors made by ESL tertiary students in writing. English Language Teaching, 10(5), 16.

Stephens, K.K., Houser, M.L. \& Cowan, R.L. (2009). RU able to meat me: the impact of students' overly casual email messages to instructors. Communication Education, 58(3), 303-326.

Tajeddin, Z. \& Pezeshki, M. (2014). Acquisition of politeness markers in an efl context: impact of input enhancement and output tasks. RELC Journal, 45(3), 269-286.

Tak, J. (2014). Grammatical agreement errors in Korean university students' English compositions: a corpus-based study. The Jungang Journal of English Language and Literature, 56(3), 433-450.

Tytar, K. (2015). Comparative analysis of email request strategies used by native and non-native speakers of English in academic settings.

Wang, Z., Walther, J. \& Hancock, J. (2009). Social identification and interpersonal communication in computer-mediated communication: what you do versus who you are in virtual groups. Human Communication Research, 35(1), 59-85.

Yoosawat, P. \& Tangkiengsirisin, S. (2016). Effects of Grammatical and Mechanical Errors on E-mail Readers' Perceptions toward E-mail Writers. PASAAPARITAT, 31, 31-52.

Zhu, W. (2012). Polite requestive strategies in emails: An investigation of pragmatic competence of Chinese EFL learners. RELC Journal, 43(2), 217-238.

Shama-E-Shahid is a lecturer in English at International University of Scholars. She holds a Master's degree in Applied Linguistics and TESOL from University of Roehampton, London. Besides, she has completed her M.A. in English Literature from the department of English at University of Dhaka. Her research interests are: Applied Linguistics, English Language Teaching and Technology in Education. 